\begin{tabular}{|c|c|}
\hline 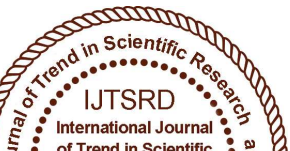 & $\begin{array}{l}\text { International Journal of Trend in Scientific } \\
\text { Research and Development (IJTSRD) }\end{array}$ \\
\hline 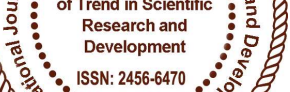 & International Open Access Journal \\
\hline 000 & ISSN No: 2456 - 6470 | www.ijtsrd.com | Volume - 2 | Issue -4 \\
\hline
\end{tabular}

\title{
Evaluation of Anti-Urolithiasis Activity in Coffea Arabica.Linn using Struvite Crystal Growth Inhibition Assay
}

\author{
G. Rathiga \\ PG Scholar, Department of Maruthuvam, \\ National Institute of Siddha, Chennai, India
}

\author{
M. Mohammed Fharook \\ PG Scholar, Department of Gunapadam, \\ Government Siddha Medical College, Chennai, India
}

\section{ABSTRACT}

Struvite accounts for $15-20 \%$ of all renal calculi. ${ }^{[1]}$ These stones can grow rapidly forming 'straghorn calculi', which is a more painful urological disorder threatening human life particularly the women. ${ }^{[2]}$ The present work was aimed to grow struvite crystals invitro using single diffusion gel growth technique and to understand the effect of Coffea arabica on its growth. Test drug was prepared at two-different concentrations of 0.5 and $1 \%$ dispersed in $1.0 \mathrm{M}$ magnesium acetate solution were gently poured on the set gel in the test tubes to enumerate the growth inhibition of struvite crystals. The result showed that the test drug Coffea arabica has anti -urolithiasis property in the tested medium.

Keywords: struvite, Coffea Arabica, crystallization, straghorn stone

\section{INTRODUCTION}

Struvite crystallization is related to urinary tract infection by microorganism producing urease. They are mainly the microorganism from the species of proteus. ${ }^{[3]}$ The techniques for removal of calculi such as, endoscopic stone removal lithotripsy and extra corporal shock wave lithotripsy cause traumatic effect of shock wave. Which leads to decrease in renal function. Therefore antilithic drugs from natural sources have assumed greater importance as herbal alternative which are cost effective with low side effects. ${ }^{[4]}$

These Coffea arabica were claimed to cause no bacterial resistance and other adverse effects.
However only a few studies have been conducted on the effect of the herb on the crystal growth of struvite as of the main components of renal calculi. Coffea arabica was known to possess several pharmacological effects mainly as, antioxidant, antiinflammatory, antimicrobial, diuretic, lithotriptic etc. ${ }^{[5]}$ Keeping in view the importance of Coffea arabica, the present work was aimed to study its influence on the growth of struvite crystals in vitro.

\section{MATERIAL AND METHODS:}

\section{COLLECTION OF RAW DRUG:}

Raw drug were collected from kodaikanal, these drug were authenticated by Medicinal Botany department, Arumbakkam, Chennai -106.( GSMC/MB- Voucher specimen no.39/2017). Project Id: NRS/AS/0061/06/2017.

\section{BOTANICAL CLASSIFICATION:}

Kingdom

Clade

Order

Genus

Species
Family
: Plantae

: Angiosperms

: Gentianales

: Rubiaceae

: Coffea

: Arabica. 


VERNACULAR NAMES OF COFFEA $\begin{aligned} & \text { test tubes were capped with airtight stopples. The } \\ & \text { experiment was conducted at the room temperature. } \\ & \text { ARABICA }:^{[6]}\end{aligned}$
Tamil
$\begin{aligned} & \text { Study on growth of crystal were carried out for five } \\ & \text { consecutive days. }\end{aligned}$

English : seeds of Coffee, Arabian coffee

Telugu $\quad$ Kapi-vittulu

\section{Growth Pattern of crystal in control and drug} added medium

Malayalam : Kappik-kuru

Kanata : Kapi-bija

Sanskrit : Meecha-phala.1

Arab : Bun

Hindi : Bun.

\section{METHOD OF PREPARATION:}

Seeds of Coffea arabica are roasted then make it fine powered.

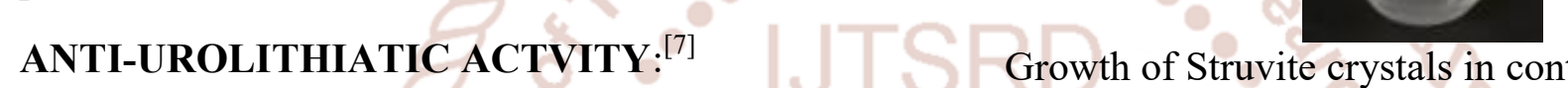

\section{Objective}

The single diffusion gel growth technique was adopted to evaluate anti-urolithiatic potential of the study drug Coffea arabica

\section{Test Drug concentration}

Test drug was prepared at two different concentrations of 0.5 and $1 \%$ dispersed in $1.0 \mathrm{M}$ magnesium acetate solution

\section{Methodology}

An aqueous solution of $0.5 \mathrm{M}$ Ammonium dihydrogen phosphate was admixed with the sodium metasilicate solution of specific gravity 1.05 in appropriate amount using magnetic stirrer so that the $\mathrm{pH}$ value $7.0 \mathrm{pH}$ of the reaction was ensured by using $\mathrm{pH}$ probe meter. The gel solution of $10 \mathrm{~mL}$ was transferred into the test tubes of $140 \mathrm{~mm}$ length and $25 \mathrm{~mm}$ diameter. After the gelation took place, $5 \mathrm{~mL}$ of supernatant solutions of 0.5 and $1 \%$ conc of test drug in $1.0 \mathrm{M}$ magnesium acetate were gently poured on the set gels in test tubes to enumerate the growth inhibition of Struvite crystals. About $5 \mathrm{ml}$ of $1.0 \mathrm{M}$ magnesium acetate without test drug were added as supernatant to control tubes which serves as crystal control group. All the procedures was done in the aseptic medium in laminar flow hood to avoid microbial contaminations. All test tubes and other glassware were autoclaved at $120^{\circ} \mathrm{C}$ for $15 \mathrm{~min}$. After pouring supernatant solution, the

Growth of Struvite crystals in control Gel medium
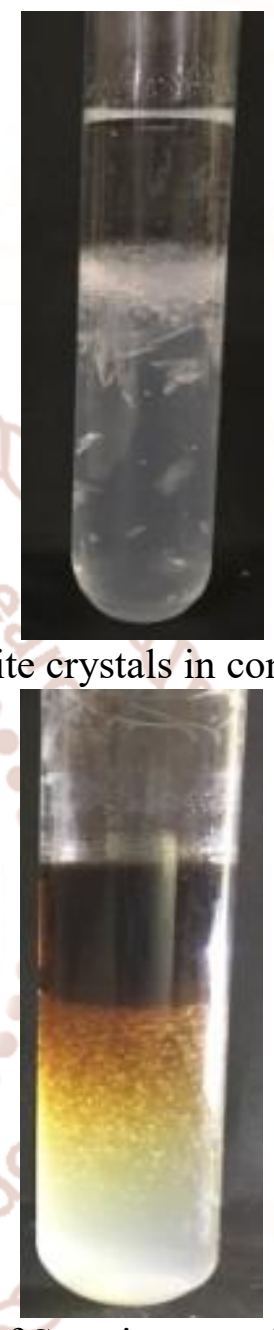

Growth of Struvite crystals in Gel medium with $0.5 \%$ of Coffea Arabica

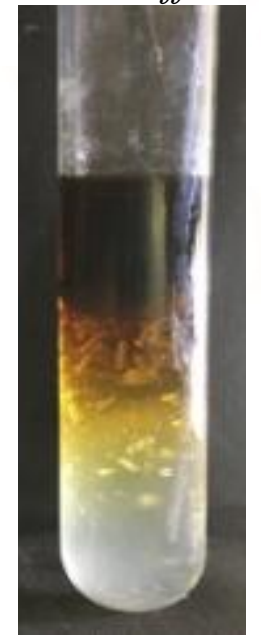

Growth of Struvite crystals in Gel medium with $1 \%$ of Coffea Arabica 


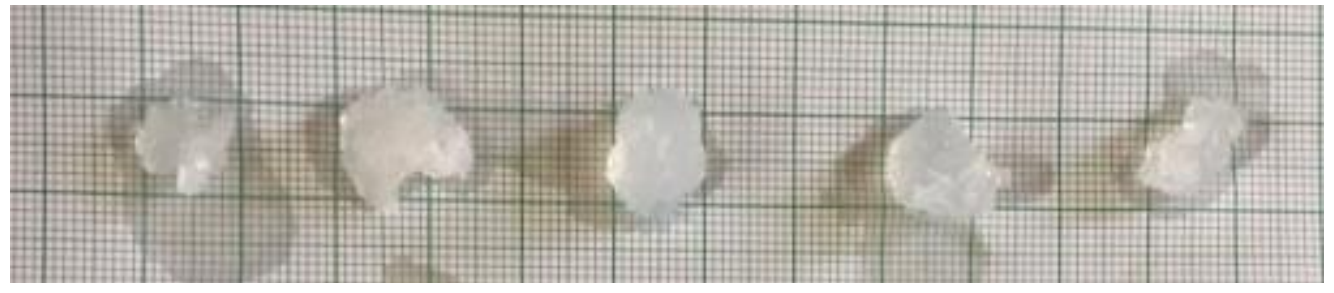

\section{A}

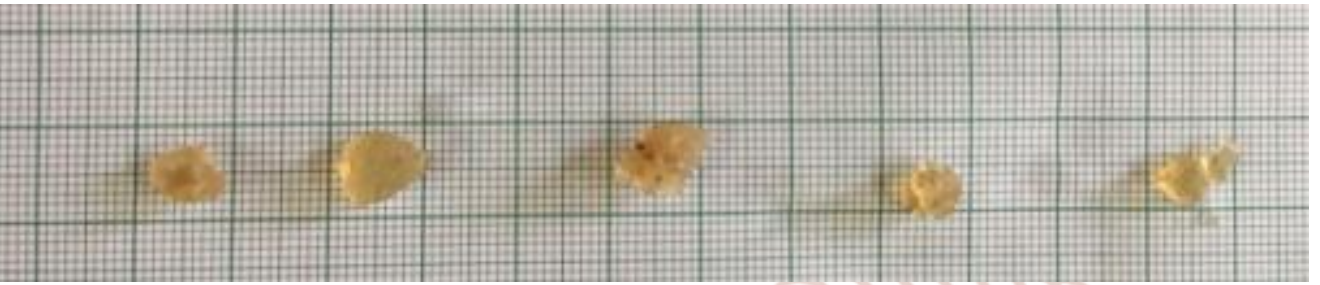

B

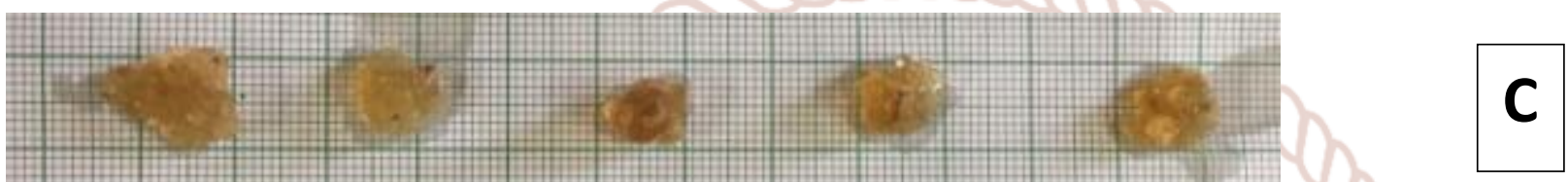

A - Size variation of Struvite crystals in Control Gel medium

B- Size variation of Struvite crystals in Gel medium with $0.5 \%$ of Coffea arabica

C- Size variation of Struvite crystals in Gel medium with $1 \%$ of Coffea Arabica

Microscopic view of Struvite crystals size after fragmentation.

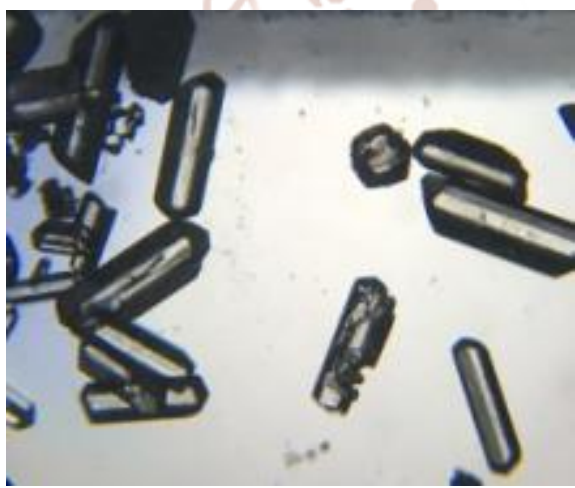

Control Gel medium

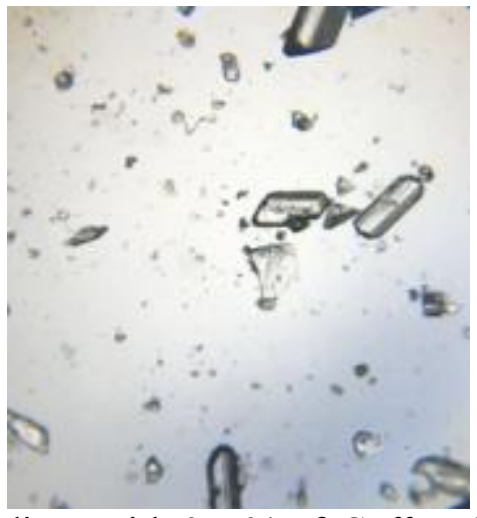

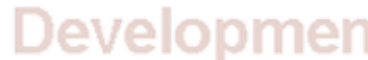

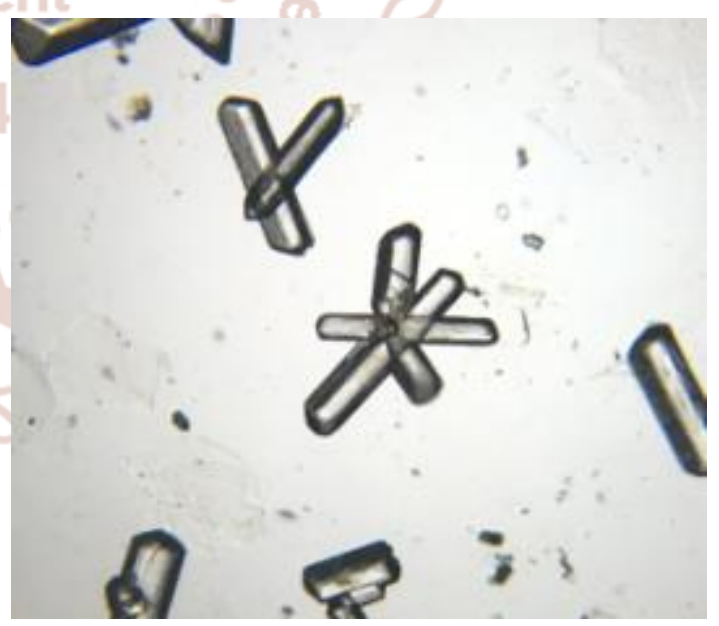

Gel medium with $1 \%$ of Coffea Arabica

\section{RESULTS AND DISSCUSSION:}

The present study investigated the anti- urolithiasis activity of Coffea Arabica using struvite crystal growth inhibition assay. This results were tabulated.

Gel medium with $0.5 \%$ of Coffea Arabica 
Report on Average Length of the Crystal in different medium

\begin{tabular}{|c|c|c|}
\hline S.No & Medium & $\begin{array}{l}\text { Average } \\
\text { Length of } \\
\text { the Crystals } \\
\text { in cm }\end{array}$ \\
\hline \multirow[t]{4}{*}{1} & Control Gel medium & \\
\hline & Mean & 1.44 \\
\hline & Std. Deviation & 0.3362 \\
\hline & Std. Error & 0.1503 \\
\hline \multirow[t]{4}{*}{2} & Gel medium + $0.5 \%$ CA & \\
\hline & Mean & 0.72 \\
\hline & Std. Deviation & 0.1304 \\
\hline & Std. Error & 0.05831 \\
\hline \multirow[t]{4}{*}{3} & Gel medium $+1 \% \mathrm{CA}$ & 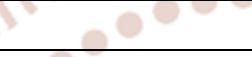 \\
\hline & Mean & 1.04 \\
\hline & Std. Deviation & 0.2608 \\
\hline & Std. Error & 0.1166 atic \\
\hline
\end{tabular}

\section{Observation}

\section{Control Medium}

Average size of the crystal was higher in the control medium with the Avg length of $1.44 \mathrm{~cm}$

\section{Gel medium $+0.5 \% \mathrm{CA}$}

Average size of the crystal was significantly decreased in medium contains $0.5 \%$ of test drug Coffea arabica with the Avg length of $0.72 \mathrm{~cm}$

Gel medium $+1 \% \mathrm{CA}$

Average size of the crystal was much reduced in medium contains $1 \%$ of test drug CP with the Coffea arabica length of $1.04 \mathrm{~cm}$.
From the result of the study it was concluded that the test drug Coffea arabica has Promising antiurolithiasis property in the tested medium.

\section{CONCLUSION:}

The stone formation process occurring in the human body is quite complex, and takes place in a dynamic environment; from the present study one can suggest that the seeds of Coffea Arabica Linn. Inhibit the growth of struvite crystals in vitro. This study may be may be used for formulating the strategy for prevention or cure.

\section{REFERENCE:}

1) Senthy sellatoray, physic-chemical basis for struvite stone formation,2011,page no.15

2) Nicki R. colledge, Devidson's principles and practice of medicine, $21^{\text {st }}$ edition,page no. 510-511.

3) Jolanta Prywer, Effect of curcumin against proteus mirablis during crystallization of struvite from artificial urine, Hidwani publishing corporation, Evidence based complementary and alternative medicine, vol 2012, 7 pages.

4) S.Kalpana, Inhibition of calcium oxalate crystallization in vitro by extract of banana cultivar monthan, International journal of pharmacy and pharmaceutical sciences, vol5,2013.

5) C.P.Khare, Natural medicine comprehensive database, An illustrated dictionary, page no 614.

6) K.S.Murukesa mudhalliyar, Siddha meteria medica,2008 edition,page no 306.

7) Chauhan, C.K., K.C. Joseph, B.B. Parekh and M.J. Joshi, 2008. Growth and characterization of Struvite crystals, Ind. J. Pure Appl. Phys., 46: 507512 